\title{
The Effect of Message Framing on Consumers' Intentions to Purchase Recycling-Aiding Products in China
}

\author{
Yang Li ${ }^{D}$, Dandan Yang * and Yingying Liu \\ Business School, Beijing Technology and Business University, 33 Fucheng Road, Beijing 100048, China; \\ girlhelen616@126.com (Y.L.); liuyingying366@163.com (Y.L.) \\ * Correspondence: tammyyang1990@163.com
}

check for updates

Citation: Li, Y.; Yang, D.; Liu, Y. The Effect of Message Framing on

Consumers' Intentions to Purchase Recycling-Aiding Products in China. Sustainability 2021, 13, 6966. https:// doi.org/10.3390/su13126966

Academic Editors: Giovanni De Feo and Flavio Boccia

Received: 14 April 2021

Accepted: 14 June 2021

Published: 21 June 2021

Publisher's Note: MDPI stays neutral with regard to jurisdictional claims in published maps and institutional affiliations.

Copyright: (c) 2021 by the authors. Licensee MDPI, Basel, Switzerland. This article is an open access article distributed under the terms and conditions of the Creative Commons Attribution (CC BY) license (https:// creativecommons.org/licenses/by/ $4.0 /)$.

\begin{abstract}
Recycling can benefit our community and the environment to a considerable degree through the link between collection and processing. Governments and companies make substantive efforts to develop effective communication strategies that encourage people to conduct recycling behaviors by using recycling-aiding products. Across three lab experiments, this research finds that negative frames are more effective in convincing consumers to purchase recycling-aiding products than positive frames. The results can be explained through perceived value and pro-environmental personal norms. Furthermore, negative frames are more effective for consumers with lower environmental involvement. To the best of our knowledge, we are the first to examine the framing effect as it applies to communicating messages about recycling-aiding products. Finally, our conclusions provide solid theoretical support and suggestions for policymakers and marketers, such as designing specific advertisements tailored to different demographics.
\end{abstract}

Keywords: message framing; waste classification; recycling-aiding products; perceived value; proenvironmental personal norms

\section{Introduction}

The World Bank's "What a Waste" global database shows that the amount of trash on Earth is expected to rise in the coming years, by some estimates, as much as $70 \%$ from 2016 to 2050. Approximately 2.1 billion tons of trash are produced annually in the whole world (China Environmental Protection Association, CEPA, 2018). According to data from the National Bureau of Statistics, the total amount of waste in China reached 242 million tons in 2019, with 10.11 million tons in Beijing alone. Recycling is the primary strategy for waste minimization, and policy makers, business managers, and scholars are committed to finding ways to increase recycling [1-3].

The Chinese government carries out series of policies of waste classification to engage the public in waste management, but it seems difficult to extend the policies nationwide. Although most people agree that waste sorting has generally been found to be preferable for environmental protection, only 13\% conducted recycling behaviors indeed [4]. It is generally understood that people need to become familiar with the standards for waste classification and then recycle different types of waste into appropriate bins, which undoubtedly increases the complexity and inaccessibility of recycling. Convenience is the key factor affecting people's participation in waste recycling [5]. That is why people do not respond to the policy of waste classification positively. In addition, unlike Western countries, waste separation in China is in its initial stage. Most Chinese families still use traditional trash cans, meaning that there may be only one wastebasket in their houses and all categories of trash are placed in it. As a result, waste containers with sorting functions are crucial in the Chinese context.

Accordingly, enterprises have released recycling-aiding products for waste classification, such as bins that are designed to keep dry and wet waste separate, to help people sort household waste quickly and conveniently. Unlike pro-environmental products-the 
products made from recycled materials or biodegradable products [6]—recycling-aiding products are designed to help people conduct recycling behaviors. However, people need to spend extra money and time to update the bins, and more importantly, they have to develop new waste disposal habits. Previous studies have shown that people are reluctant to spend money [7] and time [8] for these kinds of recycling-aiding products. As recycling behavior is a time-consuming and labor-intensive process, people need reasons or external stimuli for them to conduct recycling behavior. The government and enterprises have struggled thus far to influence the attitudes and behaviors of consumers toward recyclingaiding products. Message intervention is one of the most effective ways to address this issue [9-11]. The dry-wet separation bin, as a new type of recycling-aiding product, could transform waste disposal and solve the problem of household waste at the source with minimal effort. However, it is necessary to identify ways to encourage the adoption of this product. The main aim of this paper is to explore how to increase consumers' intentions to purchase recycling-aiding products through message intervention.

Building on Lasswell's model [12], communication strategies need to be developed with five components in mind-who, what, how, whom, and effect. Message intervention involves three essential factors in the communication process: "what", "how", and "whom". The "what" represents the strategy of the communication messages, which will be transmitted by presenting some rational elements to convince the target audience. In other words, the "what" means the message itself. The "how" relates to the form of communication and is not limited to the content of the message. The "whom" involves the process of matching, between some factors of the message and certain characteristics of the consumer and is also called the procedure of personalized matching [13]. This paper focuses on how the message is communicated and whom will be matched with recycling-aiding products.

"How" refers to the form of message expression in communication, or the message framing. Diverse message framing affects people's perspectives and affects their behavior and decision-making [14]. While scholars have begun to investigate the impact of message framing on consumer decision-making of pro-environmental products [15-17], few have considered how message framing applies to recycling-aiding products. It is generally found that traditional pro-environmental products can benefit both consumers themselves and the environment. For example, if consumers use energy-saving products, such as energy efficient light bulbs, they obtain economic benefits and save money [18]; if consumers utilize environment-friendly bags instead of plastic bags, they feel more distinctive and raise profile benefits [19]. However, the benefits of recycling-aiding products are not easily perceived, and accordingly, the stimuli of message framing are necessary to make people aware of their benefits. This study seeks to address this gap by testing the impact of message framing, as it is designed by enterprises, in the communication process. We aim to explore the impact of negative frames and positive frames on purchase intention toward recycling-aiding products and examine how such message framing influences consumers.

"Whom" refers to a specific dimension of consumer segmentation. Increasingly, scholars have been committed to examining the matching effect between the characteristic heterogeneity of audiences and message framing by considering psychological variables in the message intervention model $[20,21]$. Generally, consumers purchase bins that provide waste sorting to solve the problem of household waste recycling. As people solve problems or complete new tasks, there are two types of motivational systems: a promotion focus to help achieve goals and a prevention focus to help avoid disasters, which is called a regulatory focus [22]. Prior studies have shown that message framing has different effects on promotion-focused and prevention-focused consumers [23,24]. In our research, regulatory focus is included in the model as a dimension of consumer segmentation to test the role it plays in message intervention. In the environmental context, environmental involvement, which is the level of awareness and importance for environmental protection, is an important element affecting consumers' behavior and decision-making [25] because it is closely associated with beliefs about whether protecting the environment is important [26]. A high level of environmental involvement is a significant factor that 
enhances green purchase behavior in young consumers [27]. Gregory and Di Leo [28] showed that individuals with lower average water consumption tend to have a higher level of environmental involvement in the decision to use water. In this paper, we propose that high- and low-involvement groups have different attitudes regarding intentions to purchase recycling-aiding products. Thus, we also add environmental involvement to the research framework and treat it as a dimension of consumer segmentation to investigate its effect. In conclusion, both regulatory focus and environmental involvement serve as moderators to examine the interaction between consumers and message framing.

Another task in this paper is to explore the mechanism underlying the effect of message framing on the purchase intention toward recycling-aiding products. From the perspective of cognitive mechanisms, message framing works by enhancing the cognition and consumers' perceptions of efficacy $[17,29]$. When the recycling-aiding product communicates certain messages to consumers (e.g., functional and environmental content), consumers perceive the value of the product, such as functional value, conditional value, social value, emotional value, and epistemic value $[30,31]$. Product messages related to environmental benefits stimulate consumers' awareness of environmental responsibility, that is, pro-environmental personal norms (PPNs), which influence their purchase behavior. Thus, this paper explains two message-framing concepts that impact purchase intention toward recycling-aiding products: perceived value and PPNs.

The current study makes theoretical and substantive contributions. First, we pioneeringly introduce the message-framing effect into how information about recycling-aiding products is communicated. We examine the effect of both environmental and personal messaging to achieve an in-depth understanding of message framing's impact on purchase intention toward recycling-aiding products. Second, we clarify the boundary of the influence of message framing that plays upon environmental involvement and regulatory focus. Third, we identify the mechanism underlying the mediating effect of perceived value and PPNs. Our conclusions also offer important implications pertaining to recycling that would be relevant for policymakers and brand marketers. Especially at the level of communication strategy, it can help marketers to clarify actions in order to implement integrated communication strategies for different categories of target audiences.

\section{Theoretical Background and Hypothesis}

\subsection{Message Framing and Purchase Intention toward Recycling-Aiding Products}

Research has demonstrated that message intervention strategies usually focus on the structure, content, and channels of messages that could make consumers more willing to purchase recycling-aiding products [32]. Enterprises often transmit messages about products to consumers in certain structural ways [33]. When the message is expressed in different ways, the preferences, purchase intentions, and even decision-making of consumers will be different; the method of expression is referred to as the framing effect [34,35]. Message framing is usually divided into positive and negative message framing. The former communicates a positive consequence (gains) of the target audience taking a certain action, while the latter communicates a negative consequence (losses) of the target audience not taking the action [36].

Previous studies have identified the effect of message framing on the attitudes and behavior of consumers; however, the conclusions on the effect of different message frames are mixed. Some studies have showed that positive message framing was more effective on the attitude of the target audience than negative messages by evoking positive associations and beliefs [37], while other studies have shown that people are more likely to be convinced by the negative consequences of not acting [38]. For example, a negative frame (e.g., the risk of not participating in a chest self-test) is more persuasive than a positive frame (e.g., the benefit of participating in a chest self-test) [39]. Similarly, negatively framed messages lead to responsible behaviors, such as drinking reasonably [40] and green consumption [15].

Based on the opinion that "losses loom larger than gains" [14], the specific value related to gains might not be enough to promote people to take action, while the same 
value associated with losses might motivate people to take action. In other words, the reluctance to suffer a negative consequence is probably greater than the desire to obtain a positive consequence of the same size [41]. Diverse performance appears when people adopt different mindsets (i.e., an abstract or concrete mindset) [42]. In terms of recyclingaiding products, people are more sensitive to the negative consequences of not acting (negative frames) relative to the positive consequences of acting (positive frames), finally resulting in the effect of negative message framing being greater than that of the positive message framing. We hypothesize:

Hypothesis 1 (H1a). Message framing can significantly enhance purchase intention toward recycling-aiding products.

Hypothesis 1 (H1b). Compared with the positive frame, the negative frame has a greater effect on purchase intention toward recycling-aiding products.

\subsection{Environmental Involvement and Regulatory Focus}

As mentioned above, there is no consensus in the previous literature on the relative effects in comparison between positive and negative frames. We propose that this antinomy is partly due to the diversity of product types and consumer demographics [43]. In other words, the framing effect is limited by consumers' characteristics [44]. Therefore, when enterprises use message framing to develop communication strategies, they need to consider the compatibility of the message frames with the target audience. Our research differentiates the target audience according to two characteristics: environmental involvement and regulatory focus.

Environmental involvement has been defined by Schuhwerk and Lefkoff-Hagiu as a given individual's feelings about the importance of environmental protection [45]. To elaborate further, environmental involvement reflects an individual's attitude about the environment as well as what they think is relevant to protecting the environment. Research by Matthes and Wonneberger provides the evidence that the attitudes of individuals about the communication message of green products is affected by their environmental involvement [46]. Similarly, the high-involvement group (individuals who are highly involved in the environment) has been indicated to keep a more positive attitude toward green messages than the low-involvement group [47]. A considerable amount of research have suggested a positive relationship between highly environmental involvement and green consumption $[25,27]$. Consumers with a high level of environmental involvement are intrinsically motivated to focus on the environmental attributes of products [45] and purchase green products spontaneously, which decreases the impact between message framing and purchase intentions toward recycling-aiding products. By contrast, consumers with a low level of environmental involvement do not have a strong willingness to buy the products, so they need external message framing to enhance their purchase intention. We thus hypothesize:

Hypothesis 2 (H2). Compared with higher environmental involvement, lower environmental involvement increases the positive impact of message framing on purchase intention.

According to regulatory focus theory, all goal-directed behaviors are regulated by two different motivational systems: a promotion focus and a prevention focus [22]. A promotion focus emphasizes the positive outcomes from achieving goals, such as advancement and accomplishments, whereas a prevention focus emphasizes negative outcomes avoided from achieving goals, such as threats to security and safety. Promotion-focused individuals tend to adopt an approach strategy; in contrast, prevention-focused individuals tend to adopt avoidance strategies [48]. Previous research has shown that people discriminate outcomes when they are confronted with gain or loss frames and that discrimination is enhanced by regulatory focus [49]. For example, Chernev has pointed out that prevention-focused 
individuals are more concerned about loss and more willing to maintain the status quo, whereas promotion-focused individuals are likely to consider gains relative to maximizing positive outcomes [50]. Song and Qu have found that consumers with promotion focuses tend to perceive both the hedonic and utilitarian values of products, which leads to the experience of positive emotions through consumption, while consumers with prevention focuses are not significantly related to either hedonic or utilitarian values, which leads to the experience of negative emotions through consumption [51].

The above discussion results in the prediction that regulatory focus tends to moderate message effects on purchase intention. Prevention-focused individuals can not significantly perceive the value of recycling-aiding products from the dissemination message, and they are more sensitive to the potential loss caused by changes in existing conditions, which reduces the effectiveness of message framing on their purchase intentions. By contrast, promotion-focused individuals are more likely to be influenced by message framing, because they most likely perceive the value of and focus on the gains of purchasing the recycling-aiding products. We thus hypothesize:

Hypothesis 3 (H3). Compared with a prevention focus, a promotion focus increases the positive impact of message framing on purchase intention.

\subsection{Perceived Value and PPNs}

The third issue this study focuses on is how message framing affects purchase intention toward recycling-aiding products. Zeithaml has defined perceived value as the consumers' evaluation of the utility of a product (or service) based on their perception of benefits (e.g., capacity, quality, convenience) and costs (e.g., monetary expense, time effort) in the transaction [52]. Value concerns five dimensions: green value, perceived sacrifice, functional value, emotional value, and social value $[30,53]$. Many studies have shown that the perceived value is an important factor affecting consumers' preference and purchase intention of environmentally friendly products $[54,55]$.

In the process of consuming environmentally friendly products, consumers spend time and money (perceived sacrifice) achieving other groups' approval (social value), pleasant feelings (emotional value), the availability of products (functional value), and practicing concern for the ecological environment (green value) [56,57]. Message framing motivates consumers' perceived value from multiple dimensions. For example, when consumers are exposed to a negative message, they will perceive the monetary benefits of the product [58]. Positive message framing tends to evoke consumers' perception of quality [59]. We argue that message framing defines the green attributes and ecological benefits, then leads to higher perceived value, and finally affects consumers' purchase intention of recycling-aiding products. We thus hypothesize:

Hypothesis 4 (H4). The effect of message framing on the purchase intention toward recyclingaiding products is mediated by the perceived value.

In addition, this study proposes another interpretation path of the underlying mechanism based on the value-belief-norm theory (VBN): PPNs, which represent the informal obligations created by internalized awareness of environmental responsibility [60]. The VBN theory postulates a causal chain of five variables: values, the new ecological paradigm (NEP), the awareness of consequences (AC), the ascription of responsibility (AR), and pro-environmental personal norms (PPNs) [60]. In the causal chain, the upstream variables directly affect the downstream variables [61]. The VBN model has proven to be effective in explaining consumers' environmentally responsible actions [62,63]. Previous literature has shown the positive influence of PPNs on environmental behavior, such as the increment in the frequency of glass recycling [64] or the preference for green hotels [65]. We propose that when consumers realize what they gain from using a product (positive message framing) or what they lose from not using it (negative message framing), the exact of awareness of 
the consequences makes them feel more morally obligated to take an action (PPNs). As an important factor affecting green consumption [66], PPNs inform consumers' intentions to purchase recycling-aiding products. We thus hypothesize:

Hypothesis 5 (H5). The effect of message framing on the purchase intention toward recyclingaiding products is mediated by PPNs.

Table 1 shows the overview of studies. Three studies are conducted to examine these hypotheses (Table 1). Study 1 aims to verify H1a and H1b by examining the main effect of message framing on purchase intention toward waste-classifying, recycling-aiding products during the process of market communication. Study 2 examines the relationship between message framing and target audience to verify $\mathrm{H} 2$ and $\mathrm{H} 3$. Study 3 further examines the mechanism underlying the effect of message framing on purchase intention to verify $\mathrm{H} 4$ and H5. In order to ensure the generalization and applicability of the experiments' results, all three experiments take a type of commercially available dry-wet waste separation bin, and the product description keeps its basic information on the product's official website, but the message framing as to how the product is introduced is manipulated. Moreover, in order to reduce the influence of brand on the participants, the brand of the product is not mentioned in the three studies.

Table 1. Overview of studies.

\begin{tabular}{cccc}
\hline Study & Data Channel & Study Design & Item Collection Order \\
\hline 1 & $\begin{array}{c}\text { Online } \\
\text { Credamo }\end{array}$ & $\begin{array}{c}\text { Three (environmental message: control condition, } \\
\text { positive message, negative message) }\end{array}$ & $\begin{array}{c}\text { Three } \\
\text { (personal message: control condition, positive } \\
\text { message, negative message) }\end{array}$ \\
\hline 2 & $\begin{array}{c}\text { Online } \\
\text { Credamo }\end{array}$ & Two-level (positive message vs. negative message) & $\begin{array}{c}\text { Environmental involvement, } \\
\text { Regulatory focus, } \\
\text { Purchase intention }\end{array}$ \\
\hline 3 & $\begin{array}{c}\text { Offline } \\
\text { University }\end{array}$ & Two-level (positive message vs. negative message) & $\begin{array}{c}\text { Perceived value, } \\
\text { PPNs, } \\
\text { Purchase intention }\end{array}$ \\
\hline
\end{tabular}

\section{Study 1: Effect of Message Framing on Purchase Intention}

Study 1 examines the main effect of message framing on the purchase intention toward recycling-aiding products. We focus on both environmental and personal messages and test participants' price evaluation of products as the index of their purchase intention.

\subsection{Participants}

After removing the 11 invalid samples by operability check, two hundred and seventynine participants $\left(\mathrm{N}=279,55 \%\right.$ female, $\left.\mathrm{M}_{\mathrm{Age}}=33.3\right)$ were recruited for Study 1 via Credamo, a professional data collection platform that is utilized by many well-known universities and institutions in the world. Credamo is presently the largest data collection center in China, and it performs specialized data collection for over 1800 universities in more than 10 countries worldwide. The percentages of participants whose highest level of completed education is a bachelor's degree, postgraduate degree, and high school diploma are $51.3 \%, 28.3 \%$, and $20.4 \%$, respectively. In addition, the participants' occupation covers corporate employees, civil servants, and students. As such, the samples collected in Study 1 are characterized by diversity.

\subsection{Design}

Study 1 adopts a three (environmental message: control condition, positive message, negative message) * three (personal message: control condition, positive message, negative message) between-group design. We discuss product messages on two levels: environmen- 
tal messages and personal messages. The former shows participants what gains (positive message) or losses (negative message) can be acquired for the environment by using or not using this product; the latter shows what gains (positive message) or losses (negative message) the participants themselves can experience by using or not using this product. Moreover, a control group is added, which receives the basic information about the product without any message related to gains or losses. The experimental groups and the number of valid questionnaires are shown in Table 2.

Table 2. Groups in Study 1.

\begin{tabular}{cccc}
\hline \multirow{2}{*}{ Groups } & & \multicolumn{2}{c}{ Environmental Message } \\
\cline { 3 - 4 } & & Control Condition & Negative Message \\
\hline \multirow{2}{*}{ Personal message } & Control condition & 32 & 36 \\
& Negative message & 26 & 30 \\
& Positive message & 29 & 34 \\
\hline
\end{tabular}

\subsection{Procedure}

In Study 1, the first step is that participants who are randomly assigned to the experimental group and control group read an advertisement about the dry-wet waste separation bin. Pictures and basic information about the bins, but not personal and environmental message framing, are provided to the control group, whereas pictures, basic information, and environmental/personal messages are provided to the positive and negative groups. For example, participants in the positive message group see that "your life (personal part)/the environment will improve ... if you use the bins," and participants in the negative message group see that "your life (personal part)/environment would suffer ... if you do not use the bins."

In order to ensure that participants read the advertisement carefully, the second step is to complete four multiple-choice questions after reading. Participants then try to guess the price of the bin in the third step, and in order to get them to think more seriously about the price, we inform that participants with the closest guesses have the chance to earn a cash reward of two dollars (\$). If participants establish a higher estimated price, they are willing to pay a higher price to get the product. Generally, the higher expected price leads consumers to indicate a higher purchase intention [54]. Accordingly, in Study 1, purchase intention is operationalized as price evaluation, and the higher forecasted price implies greater purchase intention.

\subsection{Results}

Before analyzing the data, we calculated the statistically achieved power using GPower [67] considering the sample size $(\mathrm{N}=279)$ and the method of data analysis. The result shows that the computed achieved power is 0.93 . According to Cohen's argument [67], therefore, the sample of this experiment can be considered statistically competent when the computed achieved power is greater than 0.8 .

Analysis using SPSS 24.0 shows that gender's effect on the estimated price of the product is significant $\left(\mathrm{M}_{\text {Male }}=42, \mathrm{M}_{\text {Female }}=26.56, t=2.649, p<0.009\right)$. This is consistent with previous research that has found that male and female consumers hold different attitudes toward environmental protection [68,69]. There is an interaction effect between personal messages and environmental messages $(\mathrm{F}(4,270)=4.942, p<0.001)$. In order to further verify $\mathrm{H} 1$, we compare the control group with the message groups via independent sample $t$-test, and the following series of results are shown (Figure 1). First, the compared results in regard to the forecasted prices offered by the control group and personal message group (excluding the interaction group of personal environmental message) suggest that negative messages $\left(\mathrm{M}_{\mathrm{No} M F}=17.35, \mathrm{M}_{\mathrm{PN} \text { MF }}=33.81, t=-2.040, p<0.051\right)$ and positive messages $\left(\mathrm{M}_{\mathrm{No} M \mathrm{MF}}=17.35, \mathrm{M}_{\mathrm{PP} \mathrm{MF}}=27.44, t=-1.845, p<0.073\right)$ can significantly improve the personal message group's predicted prices for the bins. Moreover, the comparison 
between the control group and the environmental message group (excluding the interaction group of personal environmental messages) suggests that the construction of negative messages $\left(\mathrm{M}_{\mathrm{EN} \mathrm{MF}}=37.82, t=-2.479, p<0.018\right)$ and positive messages $\left(\mathrm{M}_{\mathrm{EP} \mathrm{MF}}=33.66\right.$, $t=-2.707, p<0.011)$ can also significantly improve the environmental message group's predicted prices for the bins.

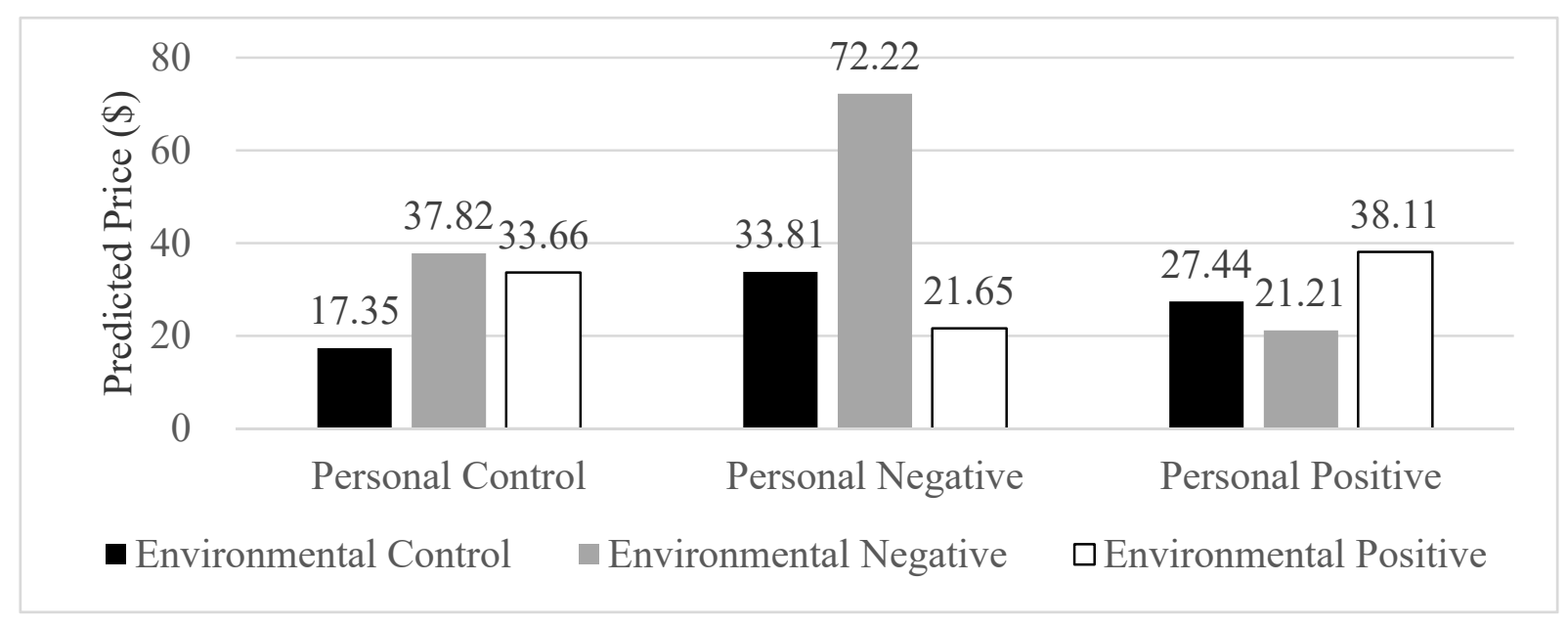

Figure 1. Study 1: Predicted price of recycling aided products by participants.

Second, we compare the data from the control group to that of the interaction group of personal environmental messages. The results demonstrate that when personal message framing matched with environmental framing-for example, when both were negative messages $\left(\mathrm{M}_{\mathrm{No} M F}=17.35, \mathrm{M}_{\mathrm{PN} \& \mathrm{EN} \mathrm{MF}}=72.22, t=-3.502, p<0.001\right)$ or positive messages $\left(\mathrm{M}_{\mathrm{PP} \& N P M F}=38.11, t=-2.013, p<0.052\right)$-the estimates for the prices of bins are significantly more accurate. However, when personal framing and environmental framing do not match-such as negative personal messages with positive environmental messages $\left(\mathrm{M}_{\mathrm{PN} \& E P M F}=21.65, t=-0.639, p>0.527\right)$ or positive personal message with negative environmental message $\left(\mathrm{M}_{\mathrm{PP} \& \mathrm{EN}} \mathrm{MF}=21.21, t=-0.952, p>0.346\right)$ - there are no significant differences in the predicted prices of the bins because the framing effect of positive frames and negative frames are offset. The above analysis shows that message framing significantly improves consumers' abilities to predict the prices of products. Thus, H1a is supported in the present study.

Finally, we analyze the positive and negative groups. There is no obvious difference in the effects of personal negative messages and the personal positive messages on price evaluation $\left(\mathrm{M}_{\mathrm{PN} M F}=33.81, \mathrm{M}_{\mathrm{PP} \mathrm{MF}}=27.44, t=0.682, p>0.499\right)$, nor in the environmental negative messages and the environmental positive messages $\left(\mathrm{M}_{\mathrm{EN} \mathrm{MF}}=37.82\right.$, $\left.\mathrm{M}_{\mathrm{EP} M F}=33.66, t=0.429, p>0.670\right)$. However, there is a significant difference between the negative framing and the positive framing of the personal-environmental interaction on the predicted prices of the bins $\left(\mathrm{M}_{\mathrm{PN} \& \mathrm{EN} \mathrm{MF}}=72.22, \mathrm{M}_{\mathrm{PP} \& \mathrm{NP} M F}=38.11, t=1.833, p<0.073\right)$. Thus, H1b is supported in the present study.

\subsection{Discussion}

The results show that a structured message can significantly improve the price evaluation of a product more than an unstructured message can. Furthermore, the greatest evaluation of this product's worth occurs when message framing emphasizes the negative consequences on the environment and individuals of not using the product. Study 2 continues the analysis of the matching effect between groups and message framing to examine whether the conclusion in Study 1 is applicable to all target audiences or whether different individuals respond differently to diverse message framing. 


\section{Study 2: The Match between Message Framing and the Target Audience}

Study 2 focuses on the match between message framing and the target audience, testing how different levels of environmental involvement and different regulatory focuses affect the impact of message framing.

\subsection{Participants}

For Study 2, 110 participants are collected via the Credamo platform. Five invalid questionnaires are identified through operational checks, and 105 participants $(\mathrm{N}=105$, $62 \%$ female, $\mathrm{M}_{\mathrm{Age}}=32.5,52 \%$ positive frames) are finally retained. The percentages of participants whose highest level of completed education is a postgraduate degree, bachelor's degree, and high school diploma are $60 \%, 30.5 \%$, and $9.5 \%$, respectively. The average monthly salary of the participants is 469 dollars. The participants are diverse and have different ages, salaries, educational backgrounds, and occupations.

\subsection{Design}

In Study 1, we found that interactive messages can augment consumers' evaluations of product prices, especially messages with consistent framing: personally positive and environmentally positive frames, and personally negative and environmentally negative frames. Based on this, Study 2 employs the interaction information instead of personal frames or environmental frames alone. In Study 2, we conduct a two-level (positive message vs. negative message), single-factor design. We also manipulate the message frames and measure each participant's environmental involvement and regulatory focus. In Study 2, we directly test the purchase intentions of participants to illustrate the main effect from another perspective.

\subsection{Procedure}

At the beginning of the experiment, participants complete a four-item scale to measure environmental involvement [45] (Schuhwerk and Lefkoff-Hagius, 1995) and a ten-item scale to measure regulatory focus, which includes six items to test promotion focus and four items to test prevention focus [70]. In the next step, they read the advertisement for the bins and then complete the operational tests, which are the same as the ones from Study 1. The manipulation of this step is that participants in the negative group see advertisements containing negatively framed messages, while those in the positive group are shown advertisements with positively framed messages. Finally, they score their purchase intention on a 7 -point scale $(1=$ strongly disagree, $7=$ strongly agree $)$, which includes three items [71].

\subsection{Results}

First, the results of the reliability examination of the three scales shows that: (1) after getting rid of the fourth item, Cronbach's $\alpha$ of the environmental involvement scale increases to $0.77 ;(2)$ in the promotion focus scale, after deleting the first item, Cronbach's $\alpha$ increases to 0.917 , and in the prevention focus, after removing the fourth item, Cronbach's $\alpha$ increases to 0.841 ; (3) Cronbach's $\alpha$ of purchase intention is 0.942 , and three items are finally preserved. All the Cronbach's $\alpha$ mentioned above are greater than 0.7 , which means that the reliability of the scales used in Study 2 is very positive.

Second, a regression analysis shows that the main effect of message framing on purchase intention is significant $\left(\mathrm{F}(1,103)=17.491, p<0.000, \eta^{2} p=0.145\right)$. Specifically, the purchase intention of the negative message group is remarkably higher than that of the positive group $\left(\mathrm{M}_{\text {Negative }}=5.66, \mathrm{M}_{\text {Positive }}=4.71, t=4.217, p<0.000\right)$. $\mathrm{H} 1 \mathrm{a}$ and $\mathrm{H} 1 \mathrm{~b}$ are thus tested and verified.

In addition, we examine the interaction between message framing and environmental involvement and find that message framing and environmental involvement have a significant interaction with the purchase intention toward recycling-aiding products $(\mathrm{F}(1,101)=4.566, p<0.035$, Figure 2$)$. The condition of consumers' high environmental in- 
volvement does not significantly improve purchase intention $\left(\mathrm{M}_{\text {High Involvement \& Positive }}=5.93\right.$, $\mathrm{M}_{\text {High Involvement \& Negative }}=6.08, t=0.637, p>0.1$ ). However, a greater change in purchase intention toward products occurs when consumers have low environmental involvement, and as expected, the negative framing has a more pronounced effect on increasing purchase intention than the positive framing does $\left(\mathrm{M}_{\text {Low Involvement \& Positive }}=4.12\right.$, $\mathrm{M}_{\text {Low Involvement \& Negative }}=5.08, t=3.453, p<0.001$ ). Thus, $\mathrm{H} 2$ is supported in the present study.

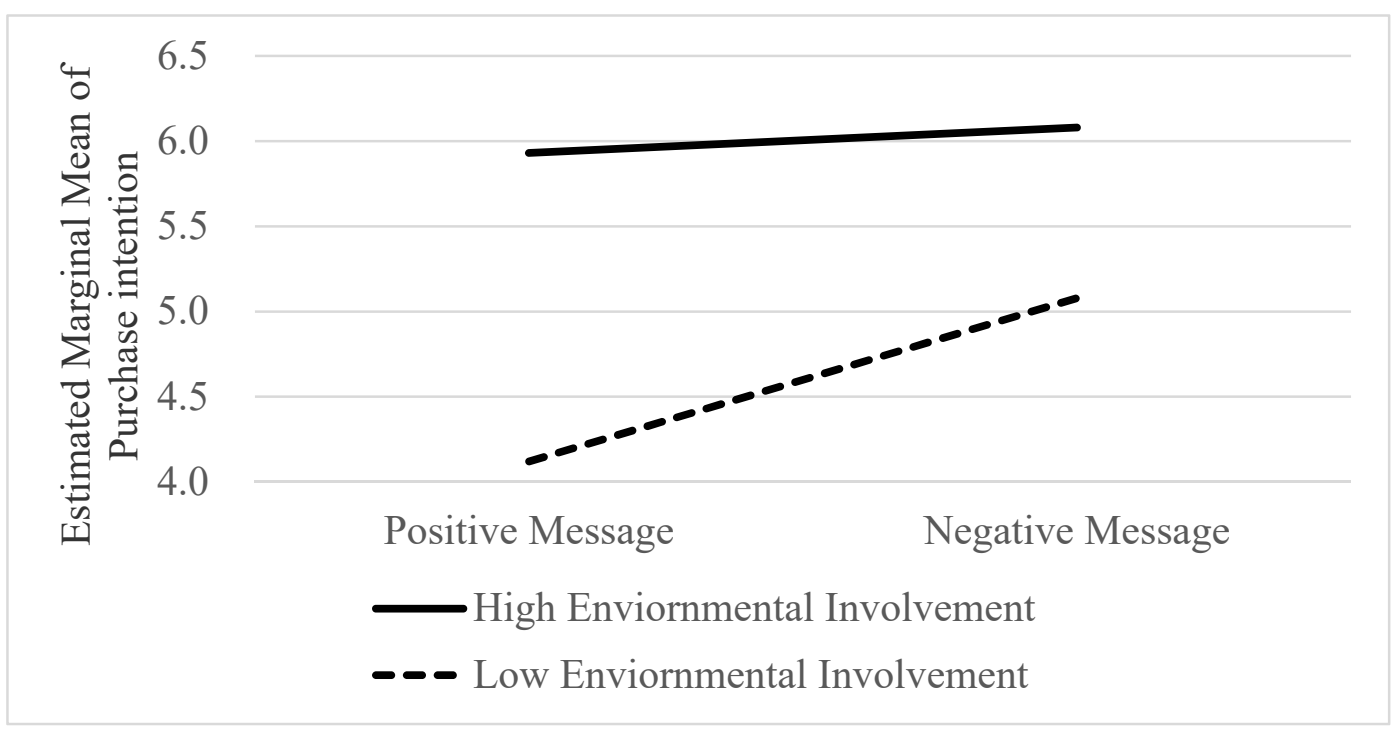

Figure 2. Study 2: the interaction between message framing and environmental involvement.

There is no evidence to suggest there is an interaction between message framing and regulatory focus in regard to purchase intention $(\mathrm{F}=0.092, p=0.762)$, which means H3 is not supported. However, we find that a regulatory focus produces a marginally significant positive impact on purchase intention $(\mathrm{F}(1,101)=175, p<0.096)$. Specifically, compared with individuals who have a prevention focus, those with a promotion focus are more inclined to purchase the products $\left(\mathrm{M}_{\text {Promotion Focus }}=5.48, \mathrm{M}_{\text {Prevention Focus }}=5.03, t=1.721\right.$, $p<0.088)$.

\subsection{Discussion}

Study 2 further demonstrates that positive and negative frames in marketing can have different influences on the purchase intention of target audiences. This suggests that the effect of message framing on purchase intention varies with different target audiences. Consumers with a high environmental involvement are more willing to buy recyclingaiding products; thus, they are not easily influenced by message framing. In contrast, consumers with low environmental involvement have less desire to purchase recyclingaiding products, so message intervention can greatly enhance their purchase intention. We further propose that, compared with the positive frame, the negative frame has a more significant influence on target audiences with low environmental involvement. Thus, the results of Study 2 support $\mathrm{H} 2$.

Although the interaction between regulatory focus and message framing has not been effectively supported, the effect of regulatory focus on purchase intention is confirmed. The conclusion provides solid support for future research.

\section{Study 3: Mediation Analyses of Perceived Value and PPNs}

The main task of Study 3 is to explore the mechanism underlying the effect of message framing on purchase intention. In other words, the purpose of this experiment is mainly 
to explore why message framing affects people's willingness to buy. We examine the mediating role of perceived value and PPNs.

\subsection{Participants}

The results of Study 2 show that the influence of message framing on purchase intention is limited by the environmental involvement of consumers. By analyzing the Pearson correlation coefficients, it is revealed that there is a significant correlation between environmental involvement and the consumers' salary levels ( $\mathrm{r}=0.199, p<0.042)$, but a weak correlation with age $(r=0.189, p<0.105)$. Consequently, consumers' differentiated characteristics, such as different salaries or ages, can influence their own environmental involvement. To reduce the impact of participants' differences on the results of the study, undergraduates were more suitable to be selected as participants. Therefore, in this study, 90 undergraduates from a Beijing university were recruited. Similarly to Studies 1 and 2, 11 questionnaires with low validity are excluded after evaluation, and a final sample of seventy-nine ( $\mathrm{N}=79,77 \%$ female) participants is obtained. Unlike the participants with different educational backgrounds and occupations selected in Study 1 and 2, participants in Study 3 possess the same level of education as well as social status (i.e., undergraduates).

\subsection{Design}

Study 3 still uses a two-level (positive message vs. negative message) single-factor design. We manipulate message frames and measure the perceived value and PPNs of participants. The dependent measure is willingness to purchase the recycle-aiding product.

\subsection{Procedure}

The experiment is divided into three steps. The first step is to read the advertisement for the bins and then complete the operational test, just as in Study 1 and Study 2. Participants then complete an 18-item scale to measure perceived value, which refers to the research of Yang and Zhou [53] on the dimension of perceived value of green products, though we adjusted some of our questions for the characteristics of the products in this study. Moreover, they also need to complete a nine-item scale to measure PPNs [60]. In the end, they score their purchase intention on a 7-point scale, which is the same as Study 2.

\subsection{Results}

We first examine the reliability of the scale (Cronbach's $\alpha_{\text {Perceived Value }}=0.936$, Cronbach's $\alpha_{\text {PPNs }}=0.926$ ), which means that the analysis based on the scale is highly credible. We conduct mediation analyses (Hayes 2018 PROCESS [72], Model 4, 5000 bootstrap samples; Figure 3) to test the downstream effects of message framing (negative message framing $=1$, positive message framing $=2$ ) on the purchase intention toward products. The results show that message framing increases the perceived value $(\mathrm{a}=-0.472, \mathrm{SE}=0.171$, $t=-2.762, p<0.007)$, which in turn increases the intention to purchase products $(\mathrm{b}=0.758$, $\mathrm{SE}=0.146, t=5.197, p<0.000$ ). The significant indirect effect (message framing $\rightarrow$ perceived value $\rightarrow$ purchase intention indirect effect $=-0.36$, boot SE $=0.14,95 \%$ CI: $[-0.69,-0.12]$ ) suggests that message framing increases the purchase intention by increasing the perceived value of products, supporting the mediated model. The results also show that message framing improves the PPNs of consumers $(\mathrm{a}=-0.580, \mathrm{SE}=0.162, t=-3.576$, $p<0.001)$, which in turn improves the intention to purchase products $(\mathrm{b}=0.427, \mathrm{SE}=0.154$, $t=2.779, p<0.007)$. Therefore, it can be concluded that message framing in marketing communication increases the purchase intention by increasing PPNs (Message framing $\rightarrow$ $\mathrm{PPNs} \rightarrow$ Purchase intention indirect effect $=-0.25$, boot SE $=0.13,95 \% \mathrm{CI}:[-0.60,-0.05])$. Complete mediation is obtained because the direct effect of message framing on purchase intention is not significant $\left(c^{\prime}=-0.098, \mathrm{SE}=0.224, t=-0.437, p<0.664\right)$. Thus, H4 and H5 are supported in the present study. 


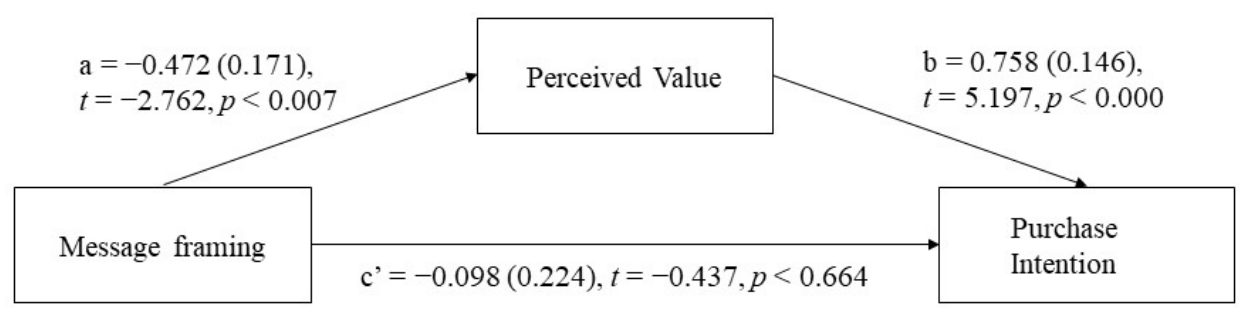

Indirect Effect $=-0.36$, boot $\mathrm{SE}=0.14,95 \% \mathrm{CI}[-0.69,-0.12]$

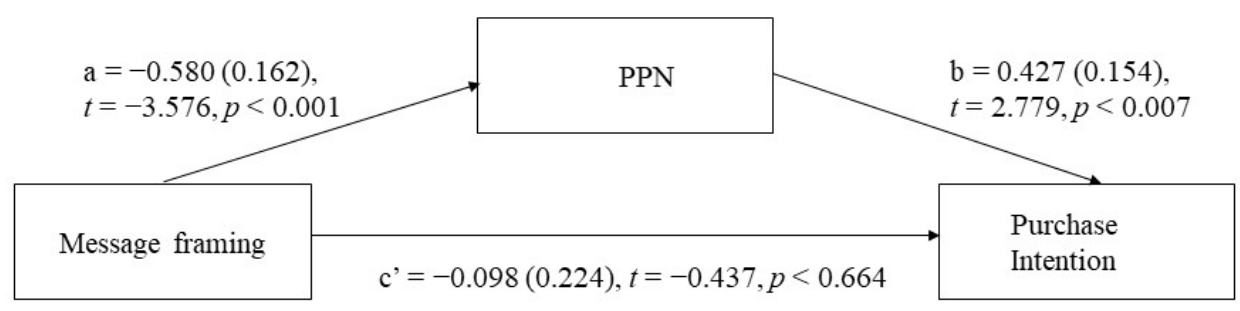

Indirect Effect $=-0.25$, boot $\mathrm{SE}=0.13,95 \% \mathrm{CI}[-0.60,-0.05]$

Hayes 2018 PROCESS, Model 4, 5,000 bootstrap samples; standard errors in parentheses

Figure 3. Study 3: perceived value and pro-environment personal norms mediate the effect of message framing on purchase intention.

\subsection{Discussion}

This study focuses on how message framing in marketing communication influences the purchase intention toward recycling-aiding products. The result suggests that perceived value and PPNs are two mediated mechanisms that help explain the effect of message framing on purchase intention. Compared with positive message framing, negative messages can significantly improve the perceived value of products and enhance the internal PPNs of consumers, which in turn increases the purchase intention toward those products. Furthermore, the indirect effect of perceived value is higher than that of PPNs, which means perceived value has a greater impact on purchase intention than do PPNs.

\section{General Discussion}

This section systematically summarizes the conclusions according to the data analysis of three experiments. These findings are not only instructive in the development and application of message framing theory, but also provide a basis for marketers to design communication strategies. At the end of the article, some limitations of this study are discussed.

\subsection{Conclusions}

This study focuses on the communication strategy for marketing recycling-aiding products, namely bins that separate different kinds of waste. In other words, our core task is to enhance the purchase intention toward recycling-aiding products through the construction of message framing. We also consider the match effect between the message framing and the target audience and test the internal mechanisms. Through the analyses of three experiments, the following conclusions can be drawn.

Message framing in the process of communication can effectively enhance consumers' willingness to purchase recycling-aiding products such as waste-classification products (Study 1). Compared with positive frames, negative frames are more likely to convince consumers to intend to buy products, which means that different message framing has a different degree of effects on the purchase intention (Study 1). This is consistent with previous studies where negative message framing was found to be more convincing to consumers than positive ones [73,74]. Negatively framed messages highlighting the detrimental environmental consequences are more effective in engaging consumers in environmental 
behavior [15]. In addition, positive messages emphasizing the presence of environmentally friendly product attributes are not as effective as messages stressing the absence of environmentally harmful attributes when it comes to altering brand attitudes [16]. The analysis of the match between message framing and targets shows there is a better match when the negative frame is directed at individuals who have low environmental involvement. In other words, for consumers who do not pay close attention to the environment, their purchase intention toward recycling-aiding products increases rapidly after being exposed to negative message framing (Study 2). The interaction between message framing and regulatory focus has not been supported, but the study finds that regulatory focus has a marginally significant effect on purchase intention, and participants with promotion focus prefer to buy the products than do those with prevention focus. Although this is only a boundary salient finding, it makes sense to have found such a trend and the significance may be improved in the future by expanding the sample size.

Mediating processes, such as the perceived value and PPNs, are examined in the conceptual model from message framing to purchase intention (Study 3). Negative message framing can make consumers realize what kinds of value (i.e., perceived value) can be brought to individuals and the environment by using recycling-aiding products, as well as realize their obligation to contribute to the environment (i.e., PPNs), which in turn increases the intention to purchase these products.

\subsection{Theoretical Implications}

This paper constructs a complete mechanism model from message framing to purchase intention, making an important theoretical contribution to the literature. First, we innovatively apply message framing to recycling-aiding products and extend the applied range of this theory. Previous work has mainly focused on one type of information [15,37]. In order to better understand the roles of different types of messages, we divide the messages into environmental messages and personal messages. Combining the two types of messages for coupling information intervention enriches and deepens the theory of message framing.

Second, this paper analyzes the connection between message framing and target audiences, and the results indicate that different message tactics should be applied to different types of consumers. In particular, groups with low levels of environmental involvement are more sensitive to message framing. This conclusion not only provides a new perspective for future research, but also provides another interpretation for the contradictions in the conclusions of previous studies, namely that they have not segmented consumers.

Third, we introduce a novel mechanism underlying the effect of message framing on purchase intention by showing that the perceived value and PPNs encourage the effects of message framing. Indeed, previous studies have focused on the main effect [75-77] while the explanations about the underlying mechanisms need to be explored in considerable depth. There are presently two branches of research on the mechanisms underlying the message framing effect. One is cognitive mechanisms, such as processing fluency [17] and perceived effort worthiness [78], which have been shown to act as mediators in the framing effect. The second are the emotional mechanisms, such as negatively framed messages that persuade consumers by eliciting fear, guilt, or shame $[79,80]$. The current research constructs a comprehensive framework that enriches the existing interpretation path and provides a solid theoretical basis for related research in the future.

\subsection{Practical Implications}

As a major component of communication strategies, message framing plays an important role in helping the government formulate the policy of waste classification, as well as help enterprises promote recycling-aiding products. According to our conclusions, the government and enterprises should pay more attention to ways of expressing messages in their communication strategies. 
When a message is transmitted in different ways, the effect will be correspondingly different. As mentioned in this study, the negative frame is more effective than the positive frame. Consequently, the government and enterprises can change the conventional way of communication (i.e., emphasizing the benefits of environmental behaviors and recyclingaiding products) into a new one (i.e., emphasizing the losses caused by non-environmental behaviors and a lack of recycling-aiding products). This can effectively enhance the public's willingness to care for the environment or purchase recycling-aiding products.

In addition, a tailoring strategy that emphasizes personalized and specific messages should be considered for marketing. The government and enterprises need to fully understand the characteristic heterogeneity of consumers and match them with the modes of the message, thus improving the accuracy and effectiveness of messages in the process of communication. For example, according to our findings, consumers with low environmental involvement are more receptive to a negative message framing, as reflected by a significant increase in their willingness to purchase environmentally friendly products. Therefore, it is advisable for companies to engage low-involvement consumers in product promotions or green marketing campaigns. Companies operating business in the green milieu or in environmentally friendly products/brands are encouraged to enhance consumer involvement in environmental issues and related green consumption [81].

\subsection{Limitations}

This study has some limitations. Although the sample size of Study 1 is acceptable according to the Gpower results, it would be better to include more participants in the future. This study has only been validated by laboratory experiments so far, and the research method is relatively homogeneous. It is suggested that the method of field experiments can be continued in the future to further validate the results in practice. As discussed earlier, we focus on the effect of message framing on purchase intention with one single product. Different message frames are used for different types of products, and thus, future research could consider adding different types of recycling-aiding products to test the generalizability of the findings. Moreover, the present research has only considered the purchase intention of recycling-aiding products rather than the actual recycling behaviors. Since there may be a gap between environmental intention and behavior [82,83]. Future studies can conduct some field experiments to observe the impact of message framing on consumers' recycling behavior.

Author Contributions: Conceptualization, methodology, writing, supervision, Y.L. (Yang Li); Writing, validation, data analysis, D.Y.; Preparation, data collection, Y.L. (Yingying Liu). All authors have read and agreed to the published version of the manuscript.

Funding: This research was funded by National Natural Science Foundation of China, Grant/Award Number: 71902005.

Institutional Review Board Statement: Not applicable.

Informed Consent Statement: Not applicable.

Data Availability Statement: Not applicable.

Conflicts of Interest: Authors declare no conflict of interest. 


\section{Nomenclature}

$\mathrm{M}_{\mathrm{No} \text { MF }} \quad$ mean value of non-message framing

MPN MF mean value of personal-negative message framing

MPP MF mean value of personal-positive message framing

$\mathrm{M}_{\mathrm{EN} M F} \quad$ mean value of environmental-negative message framing

$\mathrm{M}_{\mathrm{EP} M F} \quad$ mean value of environmental-positive message framing

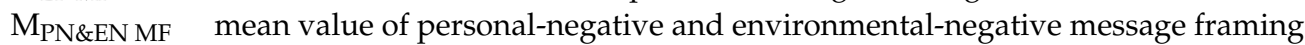

MPP\&EP MF mean value of personal-positive and environmental-positive message framing

MPN\&EP MF mean value of personal-negative and environmental-positive message framing

MPP\&EN MF mean value of personal-positive and environmental-negative message framing

\section{References}

1. Liu, J.; Bai, H.; Liang, H.; Wang, Y.; Xu, H. How to recycle the small waste household appliances in China? A revenue- expenditure analysis. Conserv. Recycl. 2018, 137, 292-301. [CrossRef]

2. Tiewa, K.G.; Basri, N.E.A.; Deng, H.; Watanabe, K.; Zain, S.M.; Wang, S. Comparative study on recycling behaviours between regular recyclers and non regular recyclers in Malaysia. J. Environ. Manag. 2019, 237, 255-263. [CrossRef]

3. Sun, M.; Trudel, R. The effect of recycling versus trashing on consumption: Theory and experimental evidence. J. Mark. Res. 2017, 54, 293-305. [CrossRef]

4. Chen, S.-J.; Li, R.-C.H.; Ma, Y.-B. Paradox between willingness and behavior: Classification mechanism of urban residents on household waste. China Population. Resour. Environ. 2015, 25, 168-176.

5. Meng, X.; Tan, X.; Wang, Y.; Wen, Z.; Tao, Y.; Qian, Y. Investigation on decision-making mechanism of residents' household solid waste classification and recycling behaviors. Resour. Conserv. Recycl. 2019, 140, 224-234. [CrossRef]

6. Tezer, A.; Bodur, H.O. The greenconsumption effect: How using green products improves consumption experience. J. Consum. Res. 2020, 47, 25-39. [CrossRef]

7. McCarty, J.A.; Shrum, L.J. The influence of individualism, collectivism, and locus of control on environmental beliefs and behavior. J. Public Policy Mark. 2001, 20, 93-104. [CrossRef]

8. Ramayah, T.; Lee, J.W.C.; Lim, S. Sustaining the environment through recycling: An empirical study. J. Environ. Manag. 2012, 102, 141-147. [CrossRef]

9. Kalamas, M.; Cleveland, M.; Laroche, M. Pro-environmental behaviors for thee but not for me: Green giants, green Gods, and external environmental locus of control. J. Bus. Res. 2014, 67, 12-22. [CrossRef]

10. Li, Y. Effect of marketing information on purchase intention for proenvironmental products in China. Soc. Behav. Personal. 2018, 46, 1215-1232. [CrossRef]

11. Liang, Y.; Henderson, L.K.; Kee, K.F. Running out of water! developing a message typology and evaluating message effects on attitude toward water conservation. Environ. Commun. 2018, 12, 541-557. [CrossRef]

12. Lasswell, H.D. The structure and function of communication in society. In The Communication of Ideas; Bryson, L., Ed.; Harper: New York, NY, USA, 1948; pp. 37-51.

13. Teeny, J.D.; Siev, J.J.; Briñol, P.; Petty, R.E. A review and conceptual framework for understanding personalized matching effects in persuasion. J. Consum. Psychol. 2021, 31, 382-414. [CrossRef]

14. Tversky, A.; Kanneman, D. The framing of decisions and the psychology of choice. Science 1981, 211, 453-458. [CrossRef]

15. Amatulli, C.; De Angelis, M.; Peluso, A.M.; Soscia, I.; Guido, G. The effect of negative message framing on green consumption: An investigation of the role of shame. J. Bus. Ethics 2019, 157, 1111-1132. [CrossRef]

16. Olsen, M.C.; Slotegraaf, R.J.; Chandukala, S.R. Green claims and message frames: How green new products change brand attitude. J. Mark. 2014, 78, 119-137. [CrossRef]

17. White, K.; Macdonnell, R.; Dahl, D.W. It's the mind-set that matters: The role of construal level and message framing in influencing consumer efficacy and conservation behaviors. J. Mark. Res. 2011, 48, 472-485. [CrossRef]

18. Tangari, A.H.; Smith, R.J. How the temporal framing of energy savings influences consumer product evaluations and choice. Psychol. Mark. 2012, 29, 198-208. [CrossRef]

19. Karmarkar, U.R.; Bollinger, B. BYOB: How bringing your own shopping bags leads to treating yourself and the environment. J. Mark. 2015, 79, 1-15. [CrossRef]

20. Jain, S.P.; Lindsey, C.; Agrawal, N.; Maheswaran, D. For better or for worse? Valenced comparative frames and regulatory focus. J. Consum. Res. 2007, 34, 57-65. [CrossRef]

21. Wu, S.; Cai, W.; Jin, S.-H. Gain or non-loss: The message matching effect of regulatory focus on moral judgements of otherorientation lies. Int. J. Psychol. 2018, 53, 223-227. [CrossRef]

22. Higgins, E.T.; Shah, J.; Friedman, R. Emotional responses to goal attainment: Strength of regulatory focus as moderator. J. Personal. Soc. Psychol. 1997, 72, 515-525. [CrossRef]

23. Lee, A.Y.; Aaker, J.L. Bringing the frame into focus: The influence of regulatory fit on processing fluency and persuasion. J. Personal. Soc. Psychol. 2004, 86, 205-218. [CrossRef] 
24. Zhao, G.; Pechmann, C. The impact of regulatory focus on adolescents' response to antismoking advertising campaigns. J. Mark. Res. 2007, 44, 671-687. [CrossRef]

25. Cheng, Z.H.; Chang, C.T.; Lee, Y.K. Linking hedonic and utilitarian shopping values to consumer skepticism and green consumption: The roles of environmental involvement and locus of control. Rev. Manag. Sci. 2018, 14, 61-85. [CrossRef]

26. Schultz, P.W.; Shriver, C.; Tabanico, J.J.; Khazian, A.M. Implicit connections with nature. J. Environ. Psychol. $2004,24,31-42$. [CrossRef]

27. Lee, K. The green purchase behavior of Hong Kong young consumers: The role of peer influence, local environmental involvement, and concrete environmental knowledge. J. Int. Consum. Mark. 2011, 23, 21-44. [CrossRef]

28. Gregory, G.D.; Di Leo, M. Repeated behavior and environmental psychology: The role of personal involvement and habit formation in explaining water consumption. J. Appl. Soc. Psychol. 2003, 33, 1261-1296. [CrossRef]

29. Obermiller, C. The baby is sick/the baby is well: A test of environmental communication appeals. J. Advert. 1995, 24, 55-70. [CrossRef]

30. Sheth, J.N.; Newman, B.I.; Gross, B.L. Why we buy what we buy: A theory of consumption values. J. Bus. Res. 1991, 22, 159-170. [CrossRef]

31. Sweeney, J.C.; Soutar, G.N. Consumer-perceived value: The development of a multiple-item scale. J. Retail. 2001, 77, 203-220. [CrossRef]

32. Goldstein, N.J.; Cialdini, R.B.; Griskevicius, V. A room with a viewpoint: Using social norms to motivate environmental conservation in hotels. J. Consum. Res. 2008, 35, 472-482. [CrossRef]

33. Chang, H.; Zhang, L.; Xie, G.-X. Message framing in green advertising: The effect of construal level and consumer environmental concern. Int. J. Advert. 2015, 34, 158-176. [CrossRef]

34. Borah, P. Conceptual issues in framing: A systematic examination of a decade's literature. J. Commun. 2011, 61, 246-263. [CrossRef]

35. Kahneman, D.; Tversky, A. Prospect theory: An analysis of decision under risk. Econometrica 1979, 47, 263-292. [CrossRef]

36. Maheswaran, D.; Meyers-Levy, J. The influence of message framing and issue involvement. J. Mark. Res. 1990, $27,361-367$. [CrossRef]

37. Lord, K.R. Motivating recycling behavior: A quasi-experimental investigation of message and source strategies. Psychol. Mark. 1994, 11, 341-358. [CrossRef]

38. Kanouse, D.E. Explaining negativity biases in evaluation and choice behavior: Theory and research. Adv. Consum. Res. 1984, 11, 703-708.

39. Levin, I.P.; Schneider, S.L.; Gaeth, G.J. All frames are not created equal: A typology and critical analysis of framing effects. Organ. Behav. Hum. Decis. Process. 1998, 76, 149-188. [CrossRef]

40. Agrawal, N.; Duhachek, A. Emotional compatibility and the effectiveness of antidrinking messages: A defensive processing perspective on shame and guilt. J. Mark. Res. 2010, 42, 263-273. [CrossRef]

41. Levin, I.P.; Gaeth, G.J.; Schreiber, J.; Lauriola, M. A new look at framing effects: Distribution of effect sizes, individual differences, and independence of types of effects. Organ. Behav. Hum. Decis. Process. 2002, 88, 411-429. [CrossRef]

42. Alter, A.L.; Oppenheimer, D.M.; Zemla, J.C. Missing the trees for the forest: A construal level account of the illusion of explanatory depth. J. Personal. Soc. Psychol. 2010, 99, 436-451. [CrossRef]

43. Block, L.G.; Keller, P.A. When to accentuate the negative: The effects of perceived efficacy and message framing on intentions to perform a health-related behavior. J. Mark. Res. 1995, 32, 192-203. [CrossRef]

44. Loroz, P.S. The interaction of message frames and reference points in prosocial persuasive appeals. Psychol. Mark. 2007, 24, 1001-1023. [CrossRef]

45. Schuhwerk, M.E.; Lefkoff-Hagius, R. Green or non-green? Does type of appeal matter when advertising a green product? J. Advert. 1995, 24, 45-54. [CrossRef]

46. Matthes, J.; Wonneberger, A. The skeptical green consumer revisited: Testing the relationship between green consumerism and skepticism toward advertising. J. Advert. 2014, 43, 115-127. [CrossRef]

47. D'Souza, C.; Taghian, M. Green advertising effects on attitude and choice of advertising themes. Asia Pac. J. Mark. Logist. 2005, 17, 51-66. [CrossRef]

48. Higgins, E.T.; Friedman, R.S.; Harlow, R.E.; Idson, L.C.; Ayduk, O.N.; Taylor, A. Achievement orientations from subjective histories of success: Promotion pride versus prevention pride. Eur. J. Soc. Psychol. 2001, 31, 3-23. [CrossRef]

49. Brendl, C.M.; Higgins, E.T.; Lemm, K.M. Sensitivity to varying gains and losses: The role of self-discrepancies and event framing. J. Personal. Soc. Psychol. 1995, 69, 1028-1051. [CrossRef]

50. Chernev, A. Goal orientation and consumer preference for the status quo. J. Consum. Res. 2004, 31, 557-565. [CrossRef]

51. Song, J.; Qu, H. How does consumer regulatory focus impact perceived value and consumption emotions? Int. J. Contemp. Hosp. Manag. 2019, 31, 285-308. [CrossRef]

52. Zeithaml, V.A. Consumer perceptions of price, quality, and value: A means-end model and synthesis of evidence. J. Mark. 1988, 52, 2-21. [CrossRef]

53. Yang, X.-Y.; Zhou, Y.-J. Green value: A new dimension of customer perceived values. China Ind. Econ. 2006, 7, 110-116.

54. Ayadi, N.; Lapeyre, A. Consumer purchase intentions for green products: Mediating role of WTP and moderating effects of framing. J. Mark. Commun. 2016, 22, 367-384. [CrossRef] 
55. Walia, S.B.; Kumar, H.; Negi, N. Impact of brand consciousness, perceived quality of products, price sensitivity and product availability on purchase intention towards 'green' products. Int. J. Technol. Manag. Sustain. Dev. 2020, 19, 107-118. [CrossRef]

56. Han, H.; Yu, J.; Kim, W. Environmentally responsible museums' strategies to elicit visitors' green intention. Soc. Behav. Personal. 2018, 46, 1881-1894. [CrossRef]

57. Wang, J.; Hsu, Y. Does sustainable perceived value play a key role in the purchase intention driven by product aesthetics? Taking smartwatch as an example. Sustainability 2019, 11, 6806. [CrossRef]

58. Gamliel, E.; Herstein, R. Involvement moderates the effect of message framing on consumers' perceived monetary gain and product choice. J. Prod. Brand Manag. 2013, 22, 142-152. [CrossRef]

59. Levin, I.P.; Gaeth, G.J. How consumers are affected by the framing of attribute information before and after consuming the product. J. Consum. Res. 1988, 15, 374-378. [CrossRef]

60. Stern, P.C.; Dietz, T.; Abel, T.; Guagnano, G.A.; Kalof, L. A value-belief-norm theory of support for social movements: The case of environmentalism. Hum. Ecol. Rev. 1999, 6, 81-97.

61. Stern, P.C. Toward a coherent theory of environmentally significant behavior. J. Soc. Issues 2000, 56, 407-424. [CrossRef]

62. Chen, M.-F. An examination of the value-belief-norm theory model in predicting pro-environmental behaviour in Taiwan. Asian J. Soc. Psychol. 2015, 18, 145-151. [CrossRef]

63. Klöckner, C. A comprehensive model of the psychology of environmental behavior-A meta-analysis. Glob. Environ. Chang. 2013, 23, 1028-1038. [CrossRef]

64. Aguilar-Luzón, M.C.; García-Martínez, J.M.A.; Calvo-Salguer, A.; Salinas, J.M. Comparative study between the theory of planned behavior and the value-belief-norm model regarding the environment, on Spanish housewives' recycling behavior. J. Appl. Soc. Psychol. 2012, 42, 2797-2833. [CrossRef]

65. Han, H. Travelers' pro-environmental behavior in a green lodging context: Converging value-belief-norm theory and the theory of planned behavior. Tour. Manag. 2015, 47, 164-177. [CrossRef]

66. Johan, J.; Agnet, M.; Annika, N. Exploring consumer adoption of a high involvement eco-innovation using value-belief-norm theory. J. Consum. Behav. 2011, 10, 51-60.

67. Cohen, J. Statistical Power Analysis for the Behavioral Sciences; Academic Press: New York, NY, USA, 1988.

68. Li, L.-Y. Effect of collectivist orientation and ecological attitude on actual environmental commitment: The moderating role of consumer demographics and product involvement. J. Int. Consum. Mark. 1997, 9, 31-53.

69. Shields, T.; Zeng, K. The reverse environmental gender gap in China: Evidence from "the China survey". Soical Sci. Q. 2012, 93, 1-20. [CrossRef]

70. Yao, Q.; Yue, G.-A.; Wu, C.-C.; Li, Y.-F.; Chen, C. Measurement of regulatory focus: The reliability and validity of Chinese version of regulatory focus questionnaire. China J. Appl. Psychol. 2008, 14, 318-323.

71. Dodds, W.B.; Monroe, K.B.; Grewal, D. Effects of price, brand, and store information on buyers' product evaluations. J. Mark. Res. 1991, 28, 307-319.

72. Hayes, A.F. Introduction to Mediation, Moderation, and Conditional Process Analysis: A Regression-Based Approach, 2nd ed.; Guilford Press, 2018; Available online: https://www.afhayes.com/introduction-to-mediation-moderation-and-conditional-processanalysis.html (accessed on 14 June 2021).

73. Rothman, A.J.; Salovey, P.; Antone, C.; Keough, K.; Martin, C.D. The influence of message framing on intentions to perform health behaviors. J. Exp. Soc. Psychol. 1993, 29, 408-433. [CrossRef]

74. Zhang, Y.; Buda, R. Moderating effects of need for cognition on responses to positively versus negatively framed advertising messages. J. Advert. 1999, 28, 1-15. [CrossRef]

75. Davis, J.J. The effects of message framing on response to environmental communications. Journal. Mass Commun. Q. 1995, 72, 285-299. [CrossRef]

76. Rothman, A.J.; Bartels, R.D.; Wlaschin, J.; Salovey, P. The strategic use of gain- and loss-framed messages to promote healthy behavior: How theory can inform practice. J. Commun. 2006, 56, S202-S220. [CrossRef]

77. Segev, S.; Fernandes, J.; Wang, W. The effects of gain versus loss message framing and point of reference on consumer responses to green advertising. J. Curr. Issues Res. Advert. 2015, 36, 35-51. [CrossRef]

78. Lagomarsino, M.; Lemarie, L.; Puntiroli, M. When saving the planet is worth more than avoiding destruction: The importance of message framing when speaking to egoistic individuals. J. Bus. Res. 2020, 118, 162-176. [CrossRef]

79. Lee-Won, R.J.; Na, K.; Coduto, K.D. The effects of social media virality metrics, message framing, and perceived susceptibility on cancer screening intention: The mediating role of fear. Telemat. Inform. 2017, 34, 1387-1397. [CrossRef]

80. Be'cheur, I.; Dib, H.; Merunka, D.; Valette-Florence, P. Emotions of fear, guilt or shame in anti-alcohol messages: Measuring direct effects on persuasion and the moderating role of sensation seeking. Eur. Adv. Consum. Res. 2007, 8, 99-106.

81. Mataraci, P.; Kurtulus, S. Sustainable marketing: The effects of environmental consciousness, lifestyle and involvement degree on environmentally friendly purchasing behavior. J. Glob. Sch. Mark. Sci. 2020, 30, 304-318. [CrossRef]

82. Morwitz, V.G.; Steckel, J.H.; Gupta, A. When do purchase intentions predict sales? Int. J. Forecast. 2007, 23, 347-364. [CrossRef]

83. Park, H.J.; Lin, L.M. Exploring attitude-behavior gap in sustainable consumption: Comparison of recycled and upcycled fashion products. J. Bus. Res. 2020, 117, 623-628. [CrossRef] 